\title{
The Innovation and Reconstruction of Marx's Thought on Community Through the Vision of a Community of Shared Future for Mankind
}

\author{
Huanhuan Zhang* \\ School of Marxism of University of Shanghai for Science and Technology, Shanghai 200093, China \\ *Corresponding author: Huanhuan Zhang, huanhuanzhang2006@126.com
}

Copyright: () 2022 Author(s). This is an open-access article distributed under the terms of the Creative Commons Attribution License (CC BY 4.0), permitting distribution and reproduction in any medium, provided the original work is cited.

\begin{abstract}
As an important theoretical thought for development, Marx's thought provides a theoretical basis for the formation and development of the world and the construction of the community. With the thorough development of the worldwide process, and on the basis of Marx's thought on community, China has put forward the vision of a community of shared future for mankind. The vision of a community of shared future for mankind is an innovative development of Marx's thought on community and is the practice of the thought of a community of shared future for mankind to achieve historical symbiosis, win-win, inclusiveness, and mutual learning.
\end{abstract}

Keywords: A community of shared future for mankind; Marx's thought on community; Innovation

Online publication: January 24, 2022

\section{The historical background formed by the vision of a community of shared future for mankind}

Building a community of shared future for mankind is a beautiful appeal to all countries in the world. As a major country, it is necessary for China to jointly tackle the crisis of global governance. There are clear conditions to build a community of shared future for mankind and to form realistic and future development goals. With the advancement of globalization, the exchanges between countries are increasing, gradually moving from ethnic groups to regions and from regions to all around the world ${ }^{[1]}$.

First of all, this is an inevitable trend of globalization. Human demand is positively correlated with the level of productivity, but with the continuous increase in productivity, human demand has become more diversified and complex. Products need to be produced in multiple links, such as different regions, different industries, and different technologies. Production itself is based on the communication among people, and the form of communication is determined by production. With the development of productive forces, the division of labor is much more detailed, the production cooperation is closer, and the production exchanges are gradually transforming the world into a real "global village."

Second, inequality and instability in international governance are increasing year by year. There is a wide gap between the rich and the poor around the world. Relying on their own capital and technological advantages, developed countries ruthlessly trample on the sovereignty of other countries, adopt an incompetent and irresponsible attitude in dealing with global problems, transfer domestic crisis to other countries, and exacerbate conflicts among developing countries ${ }^{[2]}$.

Third, resolving international crisis requires the joint effort from all countries. According to Marx's discussion in The German Ideology, it is possible to appreciate the development logic of human 
communication from production activity expansion to in-depth communication and globalization. The indepth communication upon expanding production is the reason for globalization. Due to the different interests of various countries, inevitably, there will be many crises and problems, such as international financial crisis, network security, ecological environment, major infectious diseases, and other nontraditional problems. In order to solve these problems, not only the active cooperation of all countries is required, but also it is also necessary for mankind to have the consciousness of a "community of shared future."

Fourth, China is responsible to the people around the world. All historical conflicts stem from the contradiction between productivity and mode of communication. China advocates dialogue, exchanges, and cooperation on the basis of safeguarding the common interests of all countries and disregards the traditional thinking of "zero-sum game." The practical experience of China's development has proven that a peaceful and harmonious international environment is important to national development. In order to safeguard the fundamental interests of people all over the world, it is necessary to develop "large blocks" and "large pieces," develop together, respond to opportunities and challenges, as well as share the destiny of countries

${ }^{[3]}$. China's own development is closely related to the development of other countries, which is not only the responsibility of China, but also the action and responsibility of other major countries.

\section{Influence of the vision on the creative development of Marx's thought on community}

Marx's theory of world history has been innovated and developed based on the current challenges and the vision of a community of shared future for mankind. A realistic international community has an integrated perspective of steps and continuity, so as to promote global governance and sustainable development.

\subsection{Common economic development of all countries with the concept of mutual benefit and win-win results}

The vision of a community of shared future for mankind has taken the view that productivity promotes universal human interaction and creatively developed the view that unlimited force compels capitalism to intervene in the surplus value of the world market. On the other hand, the vision of a community of shared future for mankind calls for all economies to shift from forced opening to active market integration. Since 2013, an initiative by the government has promoted substantive cooperation among countries in policy communication, facilities interconnection, barrier free trade, finance, and humanities. This cooperation has not only promoted the economic development of the areas along the line, but also provided employment opportunities and improved the living standards for the people. Unlike the dominance of capitalist expansion, it has been stressed that China's reforms should benefit all mankind ${ }^{[4]}$. All countries should enjoy equal economic development as well as promote and accelerate the development of productive forces and world economic recovery through mutual cooperation and complementary advantages. At the same time, the vision of a community of shared future for mankind clearly opposes unilateralism and protectionism, prevents winners from taking all, and alleviates the sequelae of the financial crisis. After the 2008 financial crisis, some capitalist countries went against the trend of the times and safeguarded their own interests and development through unilateralism and protectionism. In response, it has been pointed out that efforts should be made to increase the representation and voice of emerging markets and developing countries in global economic governance as well as promote the formation of a fairer and more reasonable international economic order ${ }^{[5]}$. From the regional cooperation in the ASEAN-China Free Trade Area to the successful holding of the China International Import Expo, China is striving to build a fair-trade meeting to promote the free flow of the world economy and the efficient allocation of market resources, as well as a framework for cooperation, win-win, inclusive, and prosperous economic development. The vision of a 
community of shared future for mankind, guided by the win-win concept, has broken through the productivity development dominated by capitalism, pursued the coexistence of various economies, solved the problem of de-globalization, and promoted the healthy development of economy.

\subsection{The realization of human freedom and all-round development is the ultimate value pursued by the world}

Marx took "human society" or "social humanity" as his philosophical starting point. Marx's thought of a "real community" is in fact a theory about man, which answers under what conditions man obtains liberation, development, and freedom. Marx's interest in man began with isolated and abstract individuals, and his aim was to realize individual freedom. Marx once believed that man was a free and conscious practitioner, but after discovering historical materialism, he observed man from the perspective of the whole human society. The so-called "real community" means that everyone's aim is to serve each other rather than to help one another. Everybody's free development is the condition for all people's free development. The "real community" envisaged by Marx is based on the criticism of the fantasy community of capitalism. His "real community" refers to communism. Marx stressed that the real realization of human sociality is the consistency of fundamental interests between individuals and others as well as individuals and groups, which is based on the theory of human nature and the critical study of capitalist society, without oppression or mutual oppression. Sovereign, shared destiny, and common development - the vision of a community of shared future for mankind conveys the same idea. It attaches great importance to the fate of mankind and takes the fundamental interests of mankind as the starting point. Today's world is a highly dependent world. In the context of globalization, the global crisis is particularly prominent. In the face of practical problems, the vision of a community of shared future for mankind begins from the beginning and emphasizes the consciousness of equality and cooperation. Several rationalization measures have been put forward to actively respond to the crisis. People come from different times and have different expressions, but they are to protect the fundamental interests of mankind. The vision of a community of shared future for mankind can be said to be the continuation of Marx's "real community."

\subsection{Spreading the excellent Chinese traditional culture and advocating civilized exchanges and mutual learning}

"Harmony" culture is China's traditional culture, which covers all aspects of Chinese civilization and is in a fundamental position. People have different understandings of the culture, but there is a basic consensus. The first is "harmony," which refers to the harmonious coexistence of the whole and the harmonious development of all aspects. The second is the "harmony" culture, which includes the spirit of unity between man and nature as well as the view that harmony is the most important aspect. It is the adjustment of values between man and man, man and society, as well as man and nature. The previous "harmony" culture mainly dealt with the relationship between man and nature, man and man, as well as man and family, while the vision of a community of shared future for mankind includes the relationship among countries. It only carries forward and explains the vision of a community of "harmonious" culture, shares the vision of a community of shared future for mankind, including harmonious elements, advocates the vision of joint contribution, wide consultation, and shared benefits, as well as advocates the value of "harmony without difference." It also puts forward the philosophy of win-win cooperation. With the spread of "harmony" culture, the vision of a community of shared future for mankind also advocates "world feelings." Seemingly ordinary, it actually contains a sense of responsibility and mission. This is a form of courage and a responsibility. In the realm of civilization advocated by Mencius - "being poor, you will be engulfed by self-interest, and being rich, you will benefit the world" - it can be appreciated that China's cultural heritage 
and this magnificent nation have greatly affected the Communist Party of China. Since the birth of New China to the present, the rapid development of the Chinese nation is the selfless dedication and responsibility of the Communist Party of China, which has achieved the prosperity of the motherland. The vision of a community of shared future for mankind embodies the Communist Party of China's strong sense of responsibility, not only to the Chinese people, but also to other countries. In the face of political, economic, and cultural development, the unity of the universe is important. China is promoting the formation of a community that expresses its position in the world and shares the future of mankind through peripheral cooperation and practical actions on a global scale. The relationship can be said to be stable. Harmonious coexistence and win-win cooperation are the direction of developing relations with neighboring countries along with forming strategic partnerships with Southeast Asia, Mongolia, Japan, and other countries. The aforementioned initiative is the most prominent example of a dialogue that respects history. It connects advanced areas and backward areas as well as builds a cooperation platform for common development. The central government and the initiative provide an investment platform for the eastern region, so that different countries can effectively participate in the tide of globalization.

\section{Conclusion}

In conclusion, a community of shared future for mankind is ultimately the reconstruction and creative development of Marx's "community." The ultimate goal is to achieve world peace and development, world economic prosperity, and a friendly environment. The proposal of a community of shared future for mankind is to promote the common economic development of all countries under the concept of mutual benefit and win-win as well as to realize the freedom and all-round development of human beings, which is the ultimate value pursued by the world. Through a community of shared future for mankind, China's excellent culture can be shared with the world, and the exchanges of civilizations, inclusiveness, and mutual learning around the world can be achieved.

\section{Project}

“"The Vision of a Community of Shared Future for Mankind' Criticizes and Transcends the Globalization of Capital Logic" by the Youth Project of Shanghai Philosophy and Social Science Planning (Project Number: 2018EKS010).

\section{Disclosure statement}

The author declares that there is no conflict of interest.

\section{References}

[1] Deng F, 2021, Inheritance and Innovation of the Vision of Community of Shared Future for Mankind to Marx's Thought of Community from the Perspective of Economic Globalization. Times of Fortune, 2021(09): 53-54.

[2] Yan D, 2019, A Study on the Vision of Community of Shared Future for Mankind from the Perspective of Marx's Community Thought, Changchun University of Technology.

[3] Wang C, 2019, Inheritance and Innovation of the Vision of Community of Shared Future for Mankind to Marx's Thought of Community, Zhengzhou University.

[4] Chen Y, Liu W, 2019, Inheritance and Innovation of the Leader's Vision of Community of Shared Future for Mankind on Marx's Thought of Community. Journal of Jiangxi Vocational and Technical 
College of Electricity, 32(04): 1-2, 5.

[5] Hong B, 2018, Community of Shared Future for Mankind and Marx's Community Thought: Fit, Inheritance and Innovation. Teaching and Research, 2018(10): 80-86.

Publisher's note

Bio-Byword Scientific Publishing remains neutral with regard to jurisdictional claims in published maps and institutional affiliations. 